Postgrad. MED. J. (1966), 42, 723.

Case Reports

\title{
NEUROLOGICAL COMPLICATIONS OF HODGKIN'S DISEASE
}

\author{
D. P. EYRE, M.B., Ch.B. \\ West End Hospital of Neurology and Neurosurgery, London, W.I
}

THERE have been many recent reviews of the neurological complications of Hodgkin's disease (Brit. Med. J., 1965; Hutchinson, Leonard, Maudsley and Yates, 1958; Haynal and Regli, 1964). In most of the reported cases, the diagnosis of Hodgkin's disease was established before the appearance of neurological involvement. In the case reported below the mode of presentation was neurological, and the true diagnosis was not revealed until post-operative histological examination.

\section{Case Report}

A 54-year-old labourer presented with a 25-year history of lower back pain and more recent weakness of the right leg. In 1940 while bending he felt a sudden pain in his lumbar region which radiated to both buttocks, thighs and calves. Rest in bed for the next 10 days relieved the severe pain, but from then until 1958 he had almost continuous mild backache made worse by prolonged bending, and causing him to drag his right leg the day after an attack. In 1958 lifting a heavy object was followed by a severe bout of lumbar pain which lasted 10 weeks; the pain radiated to the same areas and his right leg felt weak. In 1963 there was a further severe bout of lumbar pain which radiated to the buttocks with weakness of the right leg; this lasted five weeks and was relieved by bed rest. In June 1964 he developed pain in his right knee and was admitted to hospital. A diagnosis of a lumbar disc protrusion was made and he was treated with traction and given a corset. The pain and weakness, however, became worse. As his symptoms persisted he was transferred to the West End Hospital in January, 1965.

On examination straight leg raising on the right produced pain at $60^{\circ}$. On the left it was normal. There was $\frac{3}{8}$ inch of wasting of the right quadriceps and reduced sensation to pin and cottonwool over the right L.4. dermatome. The right knee jerk was absent, the left was normal; both ankle jerks were present and equal and both plantar responses were flexor. No other abnormality was found on neurological or general medical examination.

$\mathrm{X}$-rays of the chest were normal, those of the lumbar spine showed mild degenerative changes only. A myelogram showed a large extradural mass on the right between the lower border of $L .1$ and the body of L.4. The CSF protein concentration was $550 \mathrm{mg} . / 100 \mathrm{ml}$., with a marked increase in globulin; the Lange curve was 2111000000.

One week after admission the patient developed a bilateral lower lobe pneumonia which responded at first to penicillin but later a secondary monilial infection had to be treated with nystatin and tetracycline. Following this he developed a deep vein thrombosis in his right leg which was treated with anticoagulants. Several sputum samples failed to show any carcinoma cells.
Operation: After recovery from the pneumonia a laminectomy was performed and a large extradural mass was found which stretched from L.1. to L.4. with infiltration along the nerve roots. All the tumour mass except that along the nerve roots was removed and after decompression the cord was seen to puslate.

Histology: (Dr. Helen C. Grant): "The material consists of masses of tumour tissue which contains large quantities of fibrous tissue. In some of the fragments the fibrous tissue, which is of long standing, has compressed the neoplastic cells so that they are unrecognisable. In other fragments the tumour is evidently younger and criss-crossed by a network of younger fibrous tissue. The cells forming the tumour are variable both as to the size and shape of their nuclei and as to the quantity of cytoplasm, but in the main they are small with darkly-staining round or polygonal nuclei There is a sprinkling of larger cells with very muct larger nuclei which tend to have a heavy nuclear meng brane and in many cases have multiple nuclei. One of two of these cells are compatible in their appearance with "Sternberg-Reed" cells. Occasional mitotic figur were seen.

Conclusion: The tumour is a lymphoma and in my opinion the appearances are typical of Hodgkin's disease: the encroaching fibrous tissue and the giant cells are characteristic."

The patient made an uneventful post-operative recovery and was transferred to the Royal Marsden Hospital for radiotherapy. Here a lymphangiogram was performed which showed large glands in the right side of the pelvis and in the right para-aortic region. In view of this, radiotherapy was given to the glands as well, the dose being 4,100 rads. to the cord and 3,700 rads. to the abdominal nodes.

\section{Discussion}

Lesions of the spinal cord are a relatively frequent manifestation of neurological involvement by Hodgkin's disease. Haynal and Rigli (1964) described three examples out of 27 cases of neurological involvement by Hodgkin's but pointed out that this material came from a neuro- $D$ logical clinic and not a neurosurgical one. They quoted Weil (1931) who reported $85 \%$ of 45 cases of neuro- N logical involvement by Hodgkin's disease with spinal $\sigma$ cord involvement. In the cases of Hutchinson and others $N$ nine out of 32 cases of neurological involvement $N$ by Hodgkin's had spinal cord lesions only, and a further six had spinal cord lesions as well as other CNS lesions. The unusual feature of this case is that the extradural mass was the sole clinical evidence of Hodgkin's disease and, in fact, presented as a typical picture of a prolapsed disc: it was only after myelography that an alternative diagnosis was suspected. Indeed, it is interesting to 
speculate how much of the 25-year history of back pain was due to the presence of Hodgkin's deposit. In view of the very fibrous nature of the mass it seems reasonable to suggest that it had been there for some considerable time.

\section{Summary}

A 54-year-old man with a 25-year history of low back pain and episodes simulating acute lumbar disc prolapse was found at operation to have an extradural mass of lymphoma tissue without other clinical evidence of Hodgkin's disease.
I wish to thank Dr. E. A. Nieman, Dr. H. J. G. Bloom and Mr. Ian McCaul for permission to publish this case, and Dr. H. C. Grant and Dr. G. F. Swann for the histological and radiological reports.

\section{REFERENCES}

British Medical Journal. Leading Article, (1965); Neurological Complications of Hodgkin's Disease. i, 943.

Hutchinson, E. C., LeonaRD, B. J., Maudsley, C. and YATES, P. O. (1958): Neurological Complications of the Reticuloses. Brain, 81, 75.

Haynal, A. and REGLI, F. (1964): Neurologische Symptome bei Morbus Hodgkin. Schweiz. med. Wschr., 94, 1515.

WeIL, A. (1931): Spinal Cord Changes in Lymphogranulomatosis. Arch. Neurol. Psychiat. (Chic.), 26, 1009.

\title{
THE DANGERS OF INTERMITTENT INTRAVENOUS HEPARIN THERAPY
}

\author{
F. H. N. Spracklen, M.B., M.R.C.P. \\ Senior Registrar \\ D. G. Model, B.SC., M.B., B.S. \\ House Physician \\ E. M. M. Besterman, M.A., M.D., M.R.C.P. \\ Consultant Cardiologist
}

Department of Cardiology, St. Mary's Hospital, London, W.2

Heparin is widely used for the treatment of acute myocardial infarction, arterial embolism and venous thrombosis. Although it may be given either by the subcutaneous, intramuscular or intravenous routes, the former two methods have largely been discarded in this country due to local pain, haematomata and delay in reaching adequate levels of anticoagulation. There is also evidence that intravenous injections may be more effective therapeutically than intramuscular injections (Bauer, Boström, Jorpes and Kallner, 1950).

Repeated intravenous injections of heparin through an indwelling venous needle (e.g. Gordh needle) is comfortable for the patient and convenient for the house physician or nursing staff (Central Consultants and Specialists Committee Report, 1966) but we believe there is ample evidence to suggest there are inherent dangers in this method.

A case, recently seen, is described here. It illustrates one of the dangers of intermittent heparin treatment and it served to focus our attention on this problem.

\section{Case Report}

A 49-year-old man was admitted to hospital with an acute infero-lateral myocardial infarct. He was given 10,000 units of heparin intravenously every six hours. His recovery was uneventful until two weeks later when he developed the signs of an aortic saddle embolus. The patient was operated on by Mr. E. J. Williams who removed a large embolus from the aortic bifurcation. Emboli and fresh clot were also removed from both common iliacs, common femorals and popliteal arteries.
Post-operatively normal pulses were present in both legs and one month later a heparin tolerance test was performed.

This involved the administration of a single dose of 10,000 units of heparin with subsequent estimations of whole blood clotting times. For each estimation $1 \mathrm{ml}$. of blood was placed in each of three plain glass test tubes measuring 3 inches by $\frac{3}{8}$ inch. These were placed in a waterbath at $37^{\circ} \mathrm{C}$.

The patient's heparin tolerance curve is illustrated in the figure and compared with five control subjects, two of

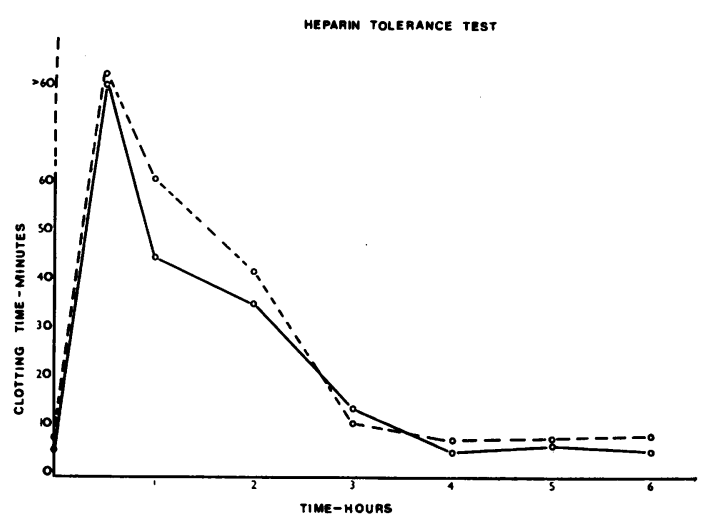

FIG. 1-The patient's clotting times are indicated by the interrupted line, the mean clotting time of the five control subjects by the continuous line. 